\title{
ANALYTICAL METHOD DEVELOPMENT AND VALIDATION OF NEW STABILITY-INDICATING REVERSE-PHASE HIGH-PERFORMANCE LIQUID CHROMATOGRAPHY METHOD FOR SIMULTANEOUS ESTIMATION OF METFORMIN HYDROCHLORIDE AND EMPAGLIFLOZIN IN TABLET DOSAGE FORM
}

\author{
GEETHA SUSMITA A*, RAJITHA G, RAMYA YADAV Y, UMA P \\ Department of Pharmaceutical Analysis, Institute of Pharmaceutical Technology, Sri Padmavathi Mahila Visvavidyalayam, \\ Tirupati - 517 502, Chittoor, Andhra Pradesh, India. Email: susmithaadepu@gmail.com
}

Received: 09 April 2018, Revised and Accepted: 25 September 2018

ABSTRACT

Objective: The objective of this study was to develop and validate a stability-indicating reverse-phase high-performance liquid chromatography (RPHPLC) method for the simultaneous estimation of the metformin and empagliflozin in tablet dosage forms.

Methods: The chromatographic conditions were optimized and it was run through Std. BDS (250 mm $\times 4.6 \mathrm{~mm}$, $5 \mathrm{~m})$ column with mobile phase consisting of $0.1 \%$ orthophosphoric acid buffer: acetonitrile in the ratio of 50:50. The flow rate was $1 \mathrm{ml} / \mathrm{min}$ and optimized wavelength was $210 \mathrm{~nm}$. Temperature was maintained at $30^{\circ} \mathrm{C}$.

Results: The retention times of metformin and empagliflozin were found to be 2.588 min and 3.679 min and percentage relative standard deviation (RSD) of the metformin and empagliflozin was found to be 0.59 and 1.2, respectively. Percentage recovery was in the range of $100.01-100.65 \%$ for metformin and empagliflozin, respectively.

Conclusion: A sensitive, rapid, and specific method has been developed for the simultaneous estimation of metformin and empagliflozin using RPHPLC in tablet dosage form.

Keywords: Metformin, Empagliflozin, Reverse-phase high-performance liquid chromatography, Validation, Stability indicating.

(C) 2019 The Authors. Published by Innovare Academic Sciences Pvt Ltd. This is an open access article under the CC BY license (http://creativecommons. org/licenses/by/4. 0/) DOI: http://dx.doi.org/10.22159/ajpcr.2019.v12i1.26537

\section{INTRODUCTION}

Metformin is chemically named as $\mathrm{N}, \mathrm{N}$-dimethyl imidodicarbonimidic diamide [1], is a biguanide antihyperglycemic agent used for treating non-insulin-dependent diabetes mellitus. It improves glycemic control by decreasing hepatic glucose production, decreasing glucose absorption, and increasing insulin-mediated glucose uptake.

Empagliflozin is chemically named as (2S, 3R, 4R, 5S, 6R)-2-[4-chloro3-(\{4-[(3S)-oxolan3-yloxy]phenyl\}methyl)phenyl]-6-(hydroxymethyl) oxane-3,4,5-triol [2]. Empagliflozin is a sodium glucose cotransporter-2 inhibitor, which lowers blood glucose in people with type 2 diabetes by blocking the reabsorption of glucose in the kidneys and promoting the excretion of excess glucose in the urine (Fig. 1).

According to the literature survey, there are only few reverse-phase high-performance liquid chromatography (RP-HPLC) methods and ultraviolet (UV) methods available for the estimation of metformin and empagliflozin individually and in combination with other drugs [3-8]. Hence, an attempt was made to develop RP-HPLC method for simultaneous estimation of metformin and empagliflozin in tablet formulation to decrease the retention times and run time. It can be adopted in regular quality control test in industries and laboratories.

\section{METHODS}

Chemicals and reagents

Acetonitrile, phosphate buffer, ammonium acetate buffer, glacial acetic acid, potassium dihydrogen phosphate, triethylamine, and orthophosphoric acid procured from Rankem Chemicals. HPLC grade methanol and water were purchased from SD Fine chemicals.
Combination of metformin and empagliflozin tablets were purchased from local market.

\section{Instrumentation}

Waters HPLC 2965 system equipped with autoinjector and photodiode array detector with Empower 2 Software was used for method development. UV-visible spectrophotometer PG Instruments T60 with a special bandwidth of $2 \mathrm{~mm}$ and $10 \mathrm{~mm}$ and matched quartz was used for spectral measurements of metformin and empagliflozin solutions.

\section{Chromatographic conditions}

The chromatographic separation and analysis were performed using a Std. BDS column $(250 \times 4.6 \mathrm{~mm}, 5 \mathrm{~m}$ particle size $)$ with the mobile phase consisting of buffer and acetonitrile in the ratio of 50:50 at a flow rate of $1 \mathrm{ml} / \mathrm{min}$ and detection wavelength was $210 \mathrm{~nm}$. Injection volume was $10 \mathrm{ml}$ and column temperature was maintained at $30^{\circ} \mathrm{C}$. Optimized chromatogram was shown in Fig. 2.

\section{Standard preparation}

Accurately weighed and transferred $34 \mathrm{mg}$ of metformin and $2 \mathrm{mg}$ of empagliflozin into a $10 \mathrm{ml}$ and $100 \mathrm{ml}$ clean, dry volumetric flasks and $3 / 4 \mathrm{ml}$ of diluent was added and sonicated for 30 minutes. Final volume was made up with diluent. $1 \mathrm{ml}$ solution was pipetted out from the above two stock solutions and transferred into a $10 \mathrm{ml}$ volumetric flask and made up to final volume with diluent. Typical chromatogram was shown in Fig. 3.

\section{Sample preparation}

A total of 20 tablets were weighed and average weight was calculated for each tablet. Then, the tablets were powdered and equivalent weight 
of one tablet was calculated. It was transferred into a $250 \mathrm{ml}$ volumetric flask $200 \mathrm{~mL}$ of diluent was added, sonicated for $25 \mathrm{~min}$. Using diluent final volume was made and filtered. $0.2 \mathrm{ml}$ was pipetted out from the filtered solution into a $10 \mathrm{ml}$ volumetric flask and final volume was made with diluent.

\section{Assay preparation}

Stock solutions of standard preparations were made from the active pharmaceutical ingredient (API) and sample preparations were prepared from formulation using appropriate diluent. Working solutions were prepared from stock solutions and both sample and standards were injected into chromatographic system for the determination of assay.

\section{Validation of HPLC method $[9,10]$}

System suitability

System suitability was carried out to check the system performance. All the essential characteristics including the percentage RSD, the United States Pharmacopeia (USP) tailing, the USP plate count, and the USP resolution were verified. The results are shown in Table 1.

\section{Specificity}

The specificity of the method was carried out by injecting blank, placebo, standard, and sample solutions into the chromatographic system. The interference of the analyte peaks with the excipients was analyzed.

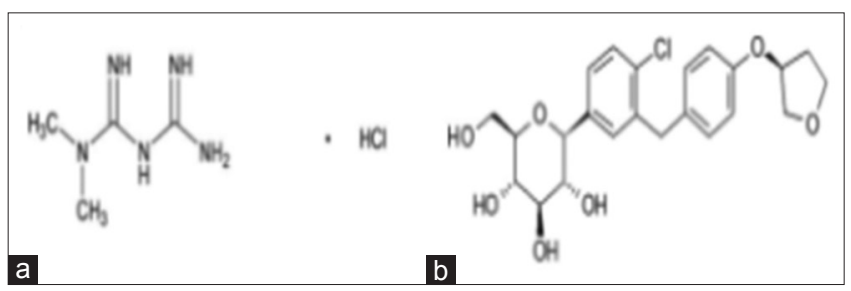

Fig. 1: (a) Chemical structure of metformin, (b) chemical structure of empagliflozin

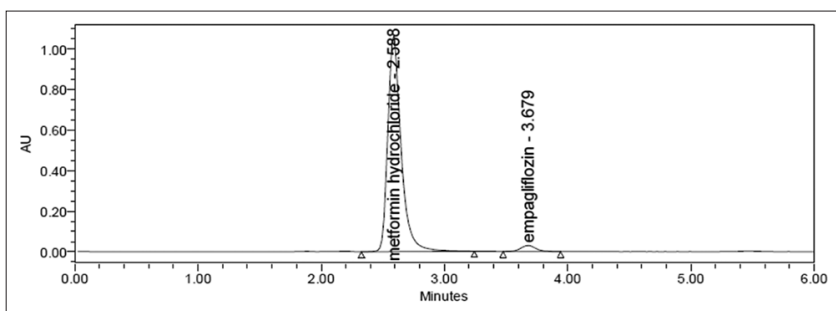

Fig. 2: Optimized chromatogram of metformin and empagliflozin

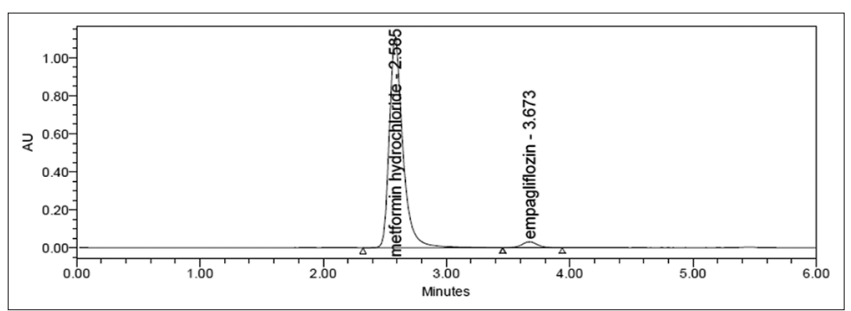

Fig. 3: Typical chromatogram of metformin and empagliflozin

Table 1: System suitability studies of metformin and empagliflozin

\begin{tabular}{lll}
\hline Property & Metformin & Empagliflozin \\
\hline RT & $2.588 \mathrm{~min}$ & $3.679 \mathrm{~min}$ \\
Theoretical plates $(\mathrm{N})$ & $2886 \pm 63.48$ & $4616 \pm 63.48$ \\
Tailing factor $(\mathrm{T})$ & $1.38 \pm 0.117$ & $1.11 \pm 0.117$ \\
\hline RT: Retention time & &
\end{tabular}

\section{Linearity}

The linearity test was performed to ensure correlation response of concentration range of the analyte and the peak area. The linearity studies were performed using stock solution containing $850 \mu \mathrm{g} / \mathrm{ml}$ and $5 \mu \mathrm{g} / \mathrm{ml}$ metformin and empagliflozin. These solutions were further diluted with diluents to yield the concentration range of 2.215$1275 \mathrm{ppm}$ and $1.25-7.5 \mathrm{ppm}$ of metformin and empagliflozin. The correlation coefficients were calculated. The calibration plots are shown in Figs. 4 and 5

\section{Precision}

The precision of the method was performed by intraday and interday variation studies. The intraday and interday studies were performed by injecting six injections of test preparations into the chromatographic system. The percentage RSD and SD were calculated. The results are presented in Table 2 .

\section{Accuracy}

The accuracy was determined by calculating the percentage recoveries of known amounts of each analyte of metformin and empagliflozin claim to the excipients, and the accuracy results were expressed as percentage of analyte recovered. The results are shown in Table 3.

\section{Limit of detection (LOD) and Limit of quantification (LOQ)}

The limit of detection (LOD) can be defined as the lowest amount of analyte in a sample can be detected and limit of quantification (LOQ) was determined as the lowest amount of analyte that was quantified. These parameters were calculated using the formula,

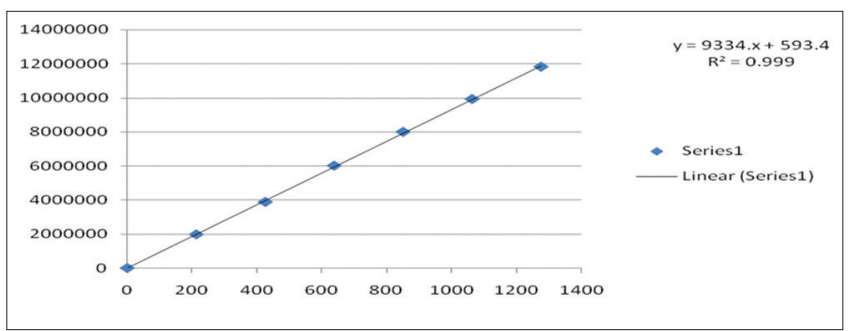

Fig. 4: Calibration plot of metformin

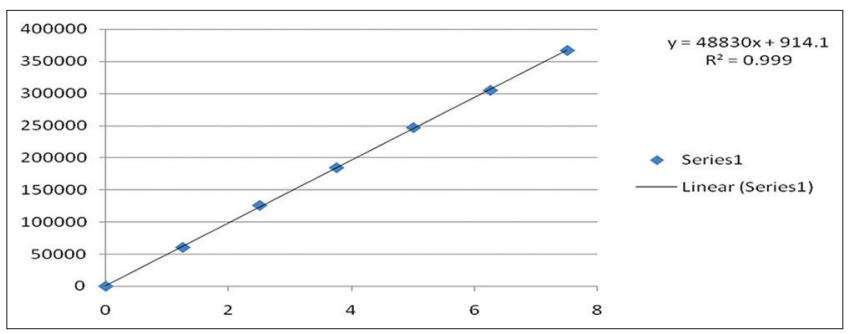

Fig. 5: Calibration plot of empagliflozin

Table 2: Intraday precision results for metformin and empagliflozin

\begin{tabular}{lll}
\hline S. No. & Metformin & Empagliflozin \\
\hline 1 & 7921030 & 250856 \\
2 & 8015260 & 245837 \\
3 & 8015344 & 247309 \\
4 & 7949328 & 246258 \\
5 & 8044578 & 241978 \\
6 & 8012992 & 249282 \\
Mean \pm SD & $7993089 \pm 47205$ & $246920 \pm 3074.3$ \\
\%RSD* & 0.59 & 1.2 \\
\hline \%RSD: Relative standard deviation
\end{tabular}


$\mathrm{LOD}=3.3 \times \mathrm{s} / \mathrm{S}$ and $\mathrm{LOQ}=10 \times \mathrm{s} / \mathrm{S}$,

Where, $\mathrm{s}=$ Standard deviation and $\mathrm{S}=$ Slope of the calibration curve.

\section{Robustness}

Robustness of the method was performed under a variety of conditions, by deliberate changes such as the composition of the mobile phase, flow rate, and temperature. The results are shown in Table 4.

\section{Forced degradation studies}

Forced degradation studies were performed to assess the stability and specificity of the proposed method. Standard and degraded samples were injected into the chromatographic system and the percentage of drug degraded in solution by applying different conditions such as acid, alkali, oxidative, photolytic, thermal, and hydrolytic analysis was calculated. The results are shown in Table 5.

\section{Oxidative degradation studies}

To $1 \mathrm{ml}$ of stock solution of metformin and empagliflozin, $1 \mathrm{ml}$ of $20 \%$ hydrogen peroxide was added separately. The solutions were kept for $30 \mathrm{~min}$ at $60^{\circ} \mathrm{C}$. For HPLC study, the resultant solution was diluted to obtain $850 \mu \mathrm{g} / \mathrm{ml}$ and $5 \mu \mathrm{g} / \mathrm{ml}$ metformin and empagliflozin and $10 \mu \mathrm{l}$ were injected into the system and the chromatograms were recorded to assess the stability of the sample.

\section{Acid degradation studies}

To $1 \mathrm{ml}$ of stock solution metformin and empagliflozin, $1 \mathrm{ml}$ of $2 \mathrm{~N}$ hydrochloric acid was added and refluxed for $30 \mathrm{~min}$ at $60^{\circ} \mathrm{C}$. The resultant solution was diluted to obtain $850 \mu \mathrm{g} / \mathrm{ml}$ and $5 \mu \mathrm{g} / \mathrm{ml}$ metformin and empagliflozin, and $10 \mu \mathrm{l}$ solutions were injected into the system and the chromatograms were recorded to assess the stability of sample.

\section{Table 3: Accuracy results for metformin and empagliflozin}

\begin{tabular}{llll}
\hline Sample & Amount added (ug/ml) & Recovery (\%) & \%RSD* \\
\hline Metformin & 425 & 100.64 & 1.41 \\
& 850 & 101.18 & 1.29 \\
\multirow{3}{*}{ Empagliflozin } & 1275 & 101.89 & 0.15 \\
& 5.5 & 101.51 & 0.97 \\
& 7.5 & 99.89 & 0.47 \\
& & 100.34 & 0.96 \\
\hline
\end{tabular}

\%RSD: Relative standard deviation

Table 4: Robustness data of metformin and empagliflozin

\begin{tabular}{llll}
\hline S. No & Robustness condition & $\begin{array}{l}\text { Metformin } \\
\text { \%RSD* }\end{array}$ & $\begin{array}{l}\text { Empagliflozin } \\
\text { \%RSD* }\end{array}$ \\
\hline 1 & Flow minus $(0.9 \mathrm{ml})$ & 0.1 & 0.3 \\
2 & Flow plus $(1.1 \mathrm{ml})$ & 0.5 & 0.7 \\
3 & Mobile phase minus & 0.3 & 0.5 \\
4 & Mobile phase plus & 0.3 & 0.4 \\
5 & Temperature minus $\left(25^{\circ} \mathrm{C}\right)$ & 0.1 & 0.1 \\
6 & Temperature plus $\left(35^{\circ} \mathrm{C}\right)$ & 0.3 & 0.8 \\
\hline
\end{tabular}

Table 5: Degradation data of metformin and empagliflozin

\begin{tabular}{|c|c|c|c|c|c|c|}
\hline \multirow[t]{2}{*}{ Type of degradation } & \multicolumn{3}{|c|}{ Metformin } & \multicolumn{3}{|c|}{ Empagliflozin } \\
\hline & Area & $\%$ recovery & $\%$ degraded & Area & $\%$ recovered & $\%$ degraded \\
\hline Acid & 7685632 & 97.45 & 2.55 & 239367 & 98.09 & 1.91 \\
\hline Peroxide & 7899186 & 98.42 & 1.58 & 239152 & 98.02 & 1.98 \\
\hline Thermal & 7924395 & 99.60 & 0.4 & 243284 & 99.10 & 0.9 \\
\hline UV & 7937101 & 99.08 & 0.92 & 243360 & 99.23 & 0.77 \\
\hline Water & 7964453 & 99.08 & 0.92 & 244395 & 99.41 & 0.59 \\
\hline
\end{tabular}

UV: Ultraviolet
To $1 \mathrm{ml}$ of stock solution metformin and empagliflozin, $1 \mathrm{ml}$ of $2 \mathrm{~N}$ sodium hydroxide was added and refluxed for $30 \mathrm{~min}$ at $60^{\circ} \mathrm{C}$. The resultant solution was diluted to obtain $850 \mu \mathrm{g} / \mathrm{ml}$ and $5 \mu \mathrm{g} / \mathrm{ml}$ metformin and empagliflozin and $10 \mu \mathrm{l}$ were injected into the system, and the chromatograms were recorded to assess the stability of the sample.

\section{Dry heat degradation studies}

The standard drug solution was placed in oven at $105^{\circ} \mathrm{C}$ for $6 \mathrm{~h}$ to study dry heat degradation. For HPLC study, the resultant solution was diluted to $850 \mu \mathrm{g} / \mathrm{ml}$ and $5 \mu \mathrm{g} / \mathrm{ml}$ metformin and empagliflozin and $10 \mu \mathrm{l}$ were injected into the system, and the chromatograms were recorded to assess the stability of the sample.

\section{Photolytic studies}

The photolytic stability of the drug was studied by exposing the $8500 \mu \mathrm{g} / \mathrm{ml}$ and $50 \mu \mathrm{g} / \mathrm{ml}$ solution for UV light by keeping the beaker in UV chamber for 7 days. For HPLC study, the resultant solutions were diluted to obtain $850 \mu \mathrm{g} / \mathrm{ml}$ and $5 \mu \mathrm{g} / \mathrm{ml}$ solutions. $10 \mu \mathrm{l}$ from above solutions were injected into the system and the chromatograms were recorded.

\section{Hydrolytic degradation studies}

Stress testing under neutral conditions was studied by refluxing the drug in water for $6 \mathrm{~h}$ at a temperature of $60^{\circ} \mathrm{C}$. For HPLC study, the resultant solution was diluted to obtain a $850 \mu \mathrm{g} / \mathrm{ml}$ and $5 \mu \mathrm{g} / \mathrm{ml}$ solution and $10 \mu \mathrm{l}$ were injected, and the chromatograms were recorded to assess the stability of the sample.

\section{RESULTS AND DISCUSSION}

A rapid reverse-phase liquid chromatography method has been developed for metformin and empagliflozin employing various ratios of mobile phases, different chromatographic conditions, and flow rates for the analysis. Under the optimal conditions of mobile phase (buffer:acetonitrile) with a ratio of 50:50 and BDS $250 \mathrm{~mm} \times 4.6 \mathrm{~mm}$, $5 \mathrm{~m}$ particle size column and flow rate of $1 \mathrm{ml} / \mathrm{min}$ satisfactory results were obtained. The retention time was found to be $2.588 \mathrm{~min}$ for metformin and $3.679 \mathrm{~min}$ for empagliflozin. The system suitability parameters, plate count, and tailing factor were within the limits with good resolution between the analyte peaks. There was no interference of excipients and mobile phase with the analyte peaks that imply the method is specific. The method showed linearity between the concentration range of $0-1275(\mathrm{ug} / \mathrm{ml})$ for metformin and 0-7.5 (ug/ml) empagliflozin. Regression equations were $y=9334.0$ $\mathrm{x}+593.4$ for metformin and $\mathrm{y}=48830 \mathrm{x}+914.1$ for empagliflozin. The calibration plot exhibits a linear relationship between peak area and concentration over a wide range. The percentage recoveries were $100.01 \%$ and $100.65 \%$ for metformin and empagliflozin, respectively. The method was robust as observed from insignificant variations in the results of analysis by changing flow rate, mobile phase, and temperature. Limit of detection values was $0.10 \mathrm{ug} / \mathrm{ml}$ and $0.31 \mathrm{ug} / \mathrm{ml}$ for metformin and empagliflozin, respectively. Limit of quantification values was $0.01 \mathrm{ug} / \mathrm{ml}$ and $0.03 \mathrm{ug} / \mathrm{ml}$, respectively, which shows the method developed is sensitive method. 


\section{CONCLUSION}

A simple and efficient method was developed for the method development and validation for simultaneous estimation of the metformin and empagliflozin by RP-HPLC in tablet dosage form. Validation was carried out as per the International Conference on Harmonisation guidelines and method validation data showing satisfactory results. Degradation studies revealed that the method is stability indicating. Hence, the proposed method can be applicable for routine quality control analysis of tablet dosage forms in laboratories.

\section{CONFLICTS OF INTEREST}

All authors have none to declare.

\section{AUTHORS' CONTRIBUTIONS}

The research was proposed and designed by G.Rajitha. The experimental work of the validated method development was carried out by Y.Ramya Yadav and A.Geetha Susmita. The manuscript was drafted by A. Geetha Susmita which was further edited by G. Rajitha. Authors read and approved the final manuscript.

\section{REFERENCES}

1. Kar M, Choudhury PK. HPLC method for estimation of metformin hydrochloride in formulated microspheres and tablet dosage form. Indian J Pharm Sci 2009;71:318-20.
2. Shyamala KN, Mounika J, Nandini B. Validated stability-indicating RP-HPLC method for determination of Empagliflozin. Pharm Lett 2016;8:457-64.

3. Venkata SM, Ram BJ, Rajan DS, Adinarayana G, Ramana MK. Development of a validated HPLC method for the estimation of metformin $\mathrm{HCl}$ and propranolol HCl. Br J Pharm Res 2014;4:1909-22.

4. Lakshmi KS, Rajesh T, Sharma S. Simultaneous determination of metformin and pioglitazone by reversed phase HPLC in pharmaceutical dosage forms. Int J Pharm Pharm Sci 2009;1:162-6.

5. Pandya RH, Rathod R, Maheswari DG. Bioanalytical method development and validation for simultaneous determination of linagliptin and metformin drugs in human plasma by RP-HPLC method. Pharmacophore 2014;5:202-18.

6. Murthy TG, Geethanjali J. Development of a validated RP-HPLC method for simultaneous estimation of metformin hydrochloride and rosuvastatin calcium in bulk and in-house formulation. J Chromatogr Sep Tech 2014;5:1-7.

7. Kavitha KY, Geetha G, Hariprasad R, Kaviarasu M, Venkatnarayanan R. Development and validation of stability indicating RP-HPLC method for the simultaneous estimation of linagliptin and metformin in pure and pharmaceutical dosage form. J Chem Pharm Res 2013;5:230-5.

8. Ramesh J, Kumar NS. Stability indicating RP-HPLC method development and validation for he simultaneous determination of vildagliptin and metformin in pharmaceutical dosage form. Int J Pharm Pharm Sci 2017;9:150-7.

9. Validation of Analytical Procedures. Text and Methodology. Geneva: Q2 (R1); 1996

10. Validation of Analytical Procedures: Text and Methodology. ICH Q2 (R1) Harmonised Tripartite Guideline; 2006;15-64. 